\title{
Gender Differences in Cognitive Abilities Among the Elderly Poor of Peru
}

\author{
Rafael Novella ${ }^{\mathrm{a}}$, Javier Olivera ${ }^{\mathrm{b}, \mathrm{c}, \boldsymbol{w}}$ \\ anter-American Development Bank \\ 凶rnovella@iadb.org \\ ${ }^{\mathrm{b}}$ Luxembourg Institute of Socio-Economic Research (LISER) \\ ${ }^{\mathrm{c}}$ Pontificia Universidad Católica del Perú, Lima, Perú \\ $\bowtie$ javier.olivera@liser.lu * Corresponding author
}

\begin{abstract}
We study gender differences on cognitive functioning among older adults living in poverty. The data come from the Survey of Health and Wellbeing of the Elderly (ESBAM) which is the baseline survey to evaluate the Peru's social pension program Pension 65. The results show that females are better off than males regarding episodic memory, but worse off in mental intactness. We do not find gender differences in the overall measure of cognition, but regional differences matter in favour of urban localities. The sizeable associations of education and quality of childhood nutrition with later-life cognition confirm the long-term impacts of early life developments on current outcomes, particularly in the case of females. Therefore, policies aimed at improving early childhood development are expected to have a positive impact in the quality of old-age.
\end{abstract}

Article History: Received: 15 April 2019 / Revised: 13 June 2019 / Accepted: 24 June 2019

Keywords: Cognition; Old age; Gender differences; Poverty; Peru.

JEL Classification: I32, J14, J24

\section{Acknowledgements}

We thank the comments and suggestions provided by two anonymous referees and the editor. 


\section{Introduction}

The decline of cognitive abilities in old age is a well-documented fact in human biology and also in social sciences thanks to the emergence of large-scale and representative household surveys aimed at assessing the well-being of the elderly. As any other indicator of accumulated human capital, cognitive ability also depreciates at a certain rate. As noted by McFadden (2008) individuals can take some measures for cognitive maintenance or repair in order to delay or smooth cognitive depreciation. Working is an important protective measure against the accelerated decline of cognition in old age as shown by Rohwedder and Willis (2010). Apart from labour, some other factors such as education, health conditions and nutritional status are also important in explaining the stock of cognitive abilities and the rate of decline. Once all of these factors - which might have affected males and females differently across lifetime-, are taken into account, one would not expect gender differences in cognition in later-life. Lee et al. (2014) report some studies suggesting that in developed countries there are not significant gender differences in cognitive functioning, while in developing countries there are important differences to the detriment of women. The usual explanation for this disparity in developing countries is rooted in important gender differences in educational attainment and nutrition in early childhood. These results lend support for calling for equalizing opportunities in accessing education between boys and girls as a vehicle to enhance cognition in old-age and to reduce disparities.

Cognitive impairments in old age make individuals less autonomous and less capable of making decisions, ranging from daily activities to more complex choices such as financial decisions. In addition, the relative size of the elderly population is growing in the majority of countries because of the demographic transition. More specifically, the proportion of elderly women is higher due to longer life expectancy for biological reasons. All of this might represent a major public health problem and require increasing public health expenditures. Cognitive decline also indirectly affects other family members who have to allocate resources and time to take care of the elderly individual. In this scenario, individuals with larger cognitive impairments might represent a burden for the family. For poor households, this might be even more detrimental given their budget constraints.

The literature that focuses on gender differences in old-age cognition in developing countries and rural areas is scarce, although exceptions are Lei et al. $(2012,2014)$ who utilize Chinese data, and Lee et al. (2014) who use Indian data. Although the study by Maurer (2011) investigates gender differences in cognition in old age in 7 Latin American countries, the samples are drawn only from country capitals, which are urban, richer and much more developed than other cities in the country. There is a lack of studies focusing on the elderly poor of rural or developing countries. It is possible that among the poor, gender differences in the level of education, health and nutrition indicators are less marked because all individuals are located at the bottom part of the distribution of such attributes. However, it is likely that gender differences in education and in the other variables are even more pronounced if cultural or economic reasons favouring boys over girls are more entrenched among the poor. We assess this empirical question by looking at the gender disparity in cognitive functioning among the elderly poor Peruvians from the Survey of Health and

\section{PUCP}


Well-being of the Elderly (ESBAM). This is a survey of poor individuals aged 65-80 in Peru that somewhat resembles the leading surveys on old age such as the Health and Retirement Survey (HRS) and the Survey of Health, Ageing and Retirement in Europe (SHARE). Importantly, ESBAM includes questions on cognition and a large set of socio-demographic, subjective and objective health measures.

This paper contributes to the empirical literature on gender differences in old-age cognitive abilities by controlling for a comprehensive and unique set of different confounders that are specific to the data. For example, we can control for ethnicity, community-level unobserved characteristics and bio-markers such as haemoglobin as well as arm-span measures that are able to capture adult and childhood nutrition quality. In addition, we offer empirical evidence of gender difference in a Latin-American country where preferences against girls are supposedly less important than in Asian countries. After controlling for these attributes, we find that females perform better than males in some of the cognitive measurements. In comparison to males, females have better cognitive functioning in episodic memory (measured with immediate and delayed word recall) and command (a series of commands to be orderly followed by the interviewee) but weaker functioning in orientation and drawing ability. In an overall measure of mental intactness - that includes orientation, command and drawing scores-females perform worse than males. Furthermore, we find that educational attainment and variables related to childhood and actual nutritional status are strongly associated with the level of cognitive functioning. We present evidence of differential relationship between cognition and education by sex, meaning that females could boost their cognitive abilities more than that of males if they were more educated.

The rest of the paper is organized as following. Section 2 describes the dataset and variables used in the empirical analysis. Section 3 discusses the empirical strategy. Section 4 reports and discuss the results. Section 5 presents conclusions.

\section{Data}

\subsection{The Survey of Health and Well-being of the Elderly}

ESBAM is a unique survey collected by the National Institute of Statistics of Peru (INEI) between November and December 2012 whose primary sample is composed of individuals aged 65-80 and living in a household officially classified as poor. The survey collects information about socio-economic conditions, subjective well-being, expectations, beliefs and several subjective and objective health related questions. Furthermore, ESBAM includes socio-economic questions at the household level and for each household member. All information is collected face-to-face by trained interviewers, while specialized technicians collect data on anthropological measures, arterial pressure and blood samples of the elderly. This dataset is the baseline for the evaluation of Pension 65, which is a non-contributory pension program administrated by the Ministry of Development and Social Inclusion of Peru (MIDIS).

The data was gathered in Peru's twelve departments ${ }^{1}$ (half of the total) where MIDIS had

\footnotetext{
${ }^{1}$ The Department is the first political and territorial division, the second one is the province and the third one is the district. Some districts, particularly in rural areas, are further divided in centros poblados (villages).
} 
Table 1

Sample composition in ESBAM.

\begin{tabular}{|c|c|c|c|c|c|c|c|c|c|}
\hline \multirow[b]{2}{*}{ Age group } & \multicolumn{3}{|c|}{ Male } & \multicolumn{3}{|c|}{ Female } & \multicolumn{3}{|c|}{ Total } \\
\hline & $\begin{array}{c}\text { Rural } \\
(\%)\end{array}$ & $\begin{array}{c}\text { Urban } \\
(\%)\end{array}$ & $\begin{array}{c}\text { Total } \\
\text { (n) }\end{array}$ & $\begin{array}{c}\text { Rural } \\
(\%)\end{array}$ & $\begin{array}{c}\text { Urban } \\
(\%)\end{array}$ & $\begin{array}{c}\text { Total } \\
\text { (n) }\end{array}$ & $\begin{array}{c}\text { Rural } \\
(\%)\end{array}$ & $\begin{array}{c}\text { Urban } \\
(\%)\end{array}$ & $\begin{array}{c}\text { Total } \\
\text { (n) }\end{array}$ \\
\hline $65-67$ & 56.0 & 44.0 & 441 & 67.3 & 32.7 & 591 & 42.7 & 57.3 & 1032 \\
\hline $68-70$ & 54.9 & 45.1 & 421 & 68.2 & 31.8 & 478 & 46.8 & 53.2 & 899 \\
\hline $71-73$ & 53.5 & 46.5 & 383 & 65.5 & 34.5 & 400 & 48.9 & 51.1 & 783 \\
\hline $74-76$ & 59.0 & 41.0 & 268 & 67.7 & 32.3 & 368 & 42.1 & 57.9 & 636 \\
\hline $77-80$ & 56.3 & 43.7 & 247 & 64.0 & 36.0 & 350 & 41.4 & 58.6 & 597 \\
\hline Total & 55.7 & 44.3 & 1760 & 66.7 & 33.3 & 2187 & 44.6 & 55.4 & 3947 \\
\hline
\end{tabular}

already completed the census of socio-economic variables intended to update its targeting score system SISFOH. Each household receives a score computed with variables such as material conditions, assets, incomes, education level, household size and occupation. Then, according to regional-specific thresholds, the government classifies each household as extreme poor, nonextreme poor or non-poor. This classification is used to target the recipients of social assistance in the country.

The sampling selection of ESBAM is probabilistic, independent in each department, stratified in rural/urban areas and carried out in two steps (first selecting census units or villages and then households). After dropping 65 individuals who did not answer the questionnaire for the elderly (persons with severe impairments like blindness and deafness) and the exclusion of respondents with missing values in relevant variables for the regressions, the final sample size is composed of 3,947 individuals (Table 1).

\subsection{The Cognitive Score}

ESBAM utilises a reduced version of the mini-mental state examination (MMSE) (Folstein et al., 1975) to evaluate the cognitive functioning of the elderly. ESBAM is similar to the adapted version used in the Survey on Health and Well-being of Elders (SABE) implemented during the early 2000s in seven capital cities of Latin America and the Caribbean. The goal of the reduced MMSE form is to attenuate the strong bias of education in performing the test, which is relevant for our sample of elderly poor who report low literacy rates (28\% are illiterate). Therefore, the cognition measures in this data are uniquely suited to poor and low educated populations. This is another novelty aspect of our study.

The score of cognitive functioning is computed with five questions dealing with different aspects of cognitive functioning. The first question measures orientation and asks about the day of the month, month, year and the day of week. Each correct answer receives one point. The second question measures immediate recall; three words are mentioned and the respondent has to repeat them immediately, albeit in any order. These words are again asked later (forth question) in order to measure delayed recall. A point is given for each word that is correctly answered ${ }^{2}$. The

\footnotetext{
${ }^{2}$ The same three words are applied to every individual which are arbol (tree), mesa (table) and perro (dog). When needed, the interviewer uses indigenous language (Aymara or Quechua). As Aymaras and Quechuas live in
} 
Table 2

Scores by type of cognitive test.

\begin{tabular}{lccccccc}
\hline \multirow{2}{*}{ Question type } & \multicolumn{9}{c}{ Points on correct answers (\%) } & \multicolumn{2}{c}{ Mean score } \\
& 0 & 1 & 2 & 3 & 4 & Total & \\
\hline Episodic memory & & & & & & & 5.06 \\
$\quad$ Word memory immediate recall & 0.68 & 1.57 & 13.55 & 84.19 & & 100.00 & 2.81 \\
$\quad$ Word memory delayed recall & 6.59 & 10.74 & 33.67 & 49.00 & & 100.00 & 2.25 \\
$\quad$ & & & & & & & 6.62 \\
Mental intactness & 2.25 & 7.14 & 16.92 & 30.43 & 43.25 & 100.00 & 3.05 \\
$\quad$ Orientation & 0.53 & 3.70 & 21.26 & 74.51 & & 100.00 & 2.70 \\
$\quad$ Command following & 12.72 & 87.28 & & & & 100.00 & 0.87 \\
$\quad$ Drawing & & & & & & & 1.69 \\
Total & & & & & & &
\end{tabular}

third question is a command of three actions that the respondent must follow orderly: "I will give you a piece of paper. Take this with your right hand, bend in half with both hands and place on your legs". Each correct action receives one point. In the fifth question the respondent receives a point if she is able to replicate (drawing) a picture of two intersected circles, provided that the circles do not cross more than half ${ }^{3}$. After summing up all the obtained points the overall cognitive score is divided into two main components. The first component is episodic memory and is computed by adding the correct points obtained in both questions on word memory (0 to 6 points). The second component of cognition is a measure of mental intactness which sums up the correct points obtained in the remaining questions ( 0 to 8 points). Table 2 reports the distribution of points for each test and the mean score for each component of cognition.

The cognition questions in ESBAM and our cognitive components share some similarities with those employed by Lei et al. $(2012,2014)$ using the China Health and Retirement Longitudinal Study (CHARLS). They form an index of episodic memory by averaging the scores of immediate and delayed recall from a list of 10 words. Their second measure of mental intactness (ranges from 0 to 11 ) includes the following items: mathematical reasoning (up to 5 continuing subtractions of 7 from 100), a variable indicating whether the respondent needed any explanation or aid, orientation questions (month, day, year, day of the week and season) and ability to replicate a drawing. Although our cognitive measures are not directly comparable with CHARLS because of different sample selection and questions, they are closely related. Table 3 shows gender differences in cognitive functioning conditional on age. Although there are not statistically significant differences between females and males with respect to the measure of episodic memory, females report statistically significant lower levels of mental intactness. Note that within mental intactness, there are only significant gender differences in the components of orientation and drawing but not in command. Table 3 also captures the deterioration of cognitive functioning with age.

well identified areas, specific bilingual interviewers were selected to work in certain areas.

${ }^{3}$ The measurement of drawing captures the intactness of visual-spatial abilities. 
Table 3

Gender differences in cognitive scores by age.

\begin{tabular}{|c|c|c|c|c|c|}
\hline \multicolumn{6}{|c|}{ Episodic memory } \\
\hline Age & Group Number of Obs. & Overall & Female & Male & F-M \\
\hline $65-69$ & 1635 & 5.234 & 5.253 & 5.219 & 0.035 \\
\hline $70-74$ & 1300 & 5.031 & 4.995 & 5.063 & -0.068 \\
\hline $75-80$ & 1012 & 4.829 & 4.782 & 4.861 & -0.078 \\
\hline All & 3947 & 5.063 & 5.053 & 5.072 & -0.019 \\
\hline \multicolumn{6}{|c|}{ Mental intactness } \\
\hline & & \multicolumn{4}{|c|}{ Orientation } \\
\hline $65-69$ & 1635 & 3.201 & 2.888 & 3.454 & $-0.566^{* * *}$ \\
\hline $70-74$ & 1300 & 2.982 & 2.610 & 3.323 & $-0.712^{* * *}$ \\
\hline $75-80$ & 1012 & 2.903 & 2.553 & 3.141 & $-0.588^{* * *}$ \\
\hline All & 3947 & 3.053 & 2.712 & 3.327 & $-0.615^{* * *}$ \\
\hline & & \multicolumn{4}{|c|}{ Command } \\
\hline $65-69$ & 1635 & 2.721 & 2.736 & 2.709 & 0.026 \\
\hline $70-74$ & 1300 & 2.695 & 2.676 & 2.713 & -0.036 \\
\hline $75-80$ & 1012 & 2.662 & 2.667 & 2.658 & 0.009 \\
\hline All & 3947 & 2.697 & 2.699 & 2.696 & 0.002 \\
\hline & & \multicolumn{4}{|c|}{ Drawing } \\
\hline $65-69$ & 1635 & 0.905 & 0.848 & 0.950 & $-0.102^{* * *}$ \\
\hline $70-74$ & 1300 & 0.862 & 0.799 & 0.920 & $-0.122^{* * *}$ \\
\hline $75-80$ & 1012 & 0.835 & 0.756 & 0.889 & $-0.133^{* * *}$ \\
\hline All & 3947 & 0.873 & 0.809 & 0.924 & $-0.115^{* * *}$ \\
\hline & & \multicolumn{4}{|c|}{ Total mental intactness } \\
\hline $65-69$ & 1635 & 6.827 & 6.471 & 7.114 & $-0.643^{* * *}$ \\
\hline $70-74$ & 1300 & 6.540 & 6.085 & 6.956 & $-0.870^{* * *}$ \\
\hline $75-80$ & 1012 & 6.400 & 5.976 & 6.688 & $-0.713^{* * *}$ \\
\hline All & 3947 & 6.623 & 6.220 & 6.947 & $-0.728^{* * *}$ \\
\hline
\end{tabular}

Note: The last column reports the t-test of mean differences between sexes. ${ }^{*} \mathrm{p}<0.1{ }^{* *} \mathrm{p}<0.05 * * * \mathrm{p}<0.01$.

\section{Method}

\subsection{Model Specification}

We use OLS estimation to measure gender differences in cognition among elderly individuals. The inclusion of a large set of controls, such as schooling, sex, age, urbanity, ethnic group, district-level fixed effects, and objective health indicators, to estimate cognitive ability help us to reduce a potentially omitted variable bias. We estimate the following equation:

$$
c_{i}=\alpha_{0}+\beta D_{i}^{\mathrm{fem}}+\delta X_{i}+\alpha_{d}+\varepsilon_{i}
$$

where $c_{i}$ corresponds to one of the cognitive scores mentioned above (standardized with mean equal to zero and standard deviation equal to one) of individual $i$; $D_{i}^{\text {fem }}$ is a dummy variable for whether the individual is female; $X_{i}$ is a vector of exogenous variables; $\alpha_{d}$ are district fixed effects (district of residence of individual $i$ ); and $\varepsilon_{i}$ is an error term. The coefficient on our variable of interest, $D_{i}^{\text {fem }}$, indicates the role of being female on cognitive functioning conditional on all the other attributes. 
After estimating equation (1), we further analyse gender differentials using interactions between the gender dummy and the other covariates in the regression. The aim is to explore whether cognition is associated with each covariate differently by gender. Thus, we estimate the following equation:

$$
c_{i}=\alpha_{0}+\beta D_{i}^{\mathrm{fem}}+\delta_{1} D_{i}^{\mathrm{fem}} X_{i}+\delta_{2} X_{i}+\alpha_{d}+\varepsilon_{i}
$$

In equation (2), the interaction term indicates whether there is a gender differential relationship between the covariate and cognitive functioning.

\subsection{Control Variables}

In addition to socio-demographic variables such as age, sex, urban/rural residence, ethnic group and schooling, we include district-level fixed effects to capture unobservable characteristics at the local level, such as labour market conditions, community deprivation of health and basic services, and healthy environments. Furthermore, we include objective health indicators collected in ESBAM that are expected to be related to cognitive skills such as haemoglobin, arm-span and chronic diseases related to mental health. We use haemoglobin (measured from extracted respondents' blood samples) in order to consider the role of anaemia, which is linked to an increase in the risk of dementia through low oxygen levels affecting brain connections and hence reducing memory and thinking abilities and damaging neurons (Hong et al., 2013). According to WHO norms, haemoglobin levels should be roughly between $12 \mathrm{~g} / \mathrm{dL}$ to $16 \mathrm{~g} / \mathrm{dL}$. Anemia can affect an important number of the elderly because old age is associated with diet monotony, less intestinal mobility and the intake of energy. The inclusion of this variable is aimed at measuring the role of current nutritional status.

Moreover, it is recognized that cognition performance among the elderly is positively related with nutrition quality acquired in childhood. Case and Paxson (2008) find a strong correlation between height at early life ( $<3$ years) and adulthood, so that this last variable can indicate the nutrition and health experienced at early life. In addition to these authors, Guven and Lee (2013, 2015) and Lei et al. $(2012,2014)$ also use respondent's height to find that better nutrition in childhood is positively associated with cognitive ability development. Height is not measured in ESBAM because of well-known limitations of taking this measure in old-age individuals (height shrinking, difficulty to stand straight, etc.). Instead, we use arm-span, which is considered a better measure in old-age individuals and is highly correlated with height (Kwok and Whitelaw, 1991; Kwok et al., 2002; De Lucia et al., 2002). The evidence for Latin America shows a significant positive relation between height and cognitive functioning in old age (e.g. Yount et al. (2009) for Guatemala; and Maurer (2010) for 7 capital cities using the SABE data).

We also control for some mental related chronic diseases that might affect cognition status. For example, it has been found in longitudinal studies that depression exacerbates the risk of cognitive decline among the elderly (Chodosh et al., 2007; Dotson et al., 2008). We will use a dummy variable indicating whether the respondent reported any of the following diseases diagnosed by a doctor: depression, cerebral haemorrhage and nervous system disorders, Alzheimer or memory loss. About one fifth of our sample reported at least one of these disorders. 
Table 4

Distribution of education attainment by gender and age groups (percentage).

\begin{tabular}{|c|c|c|c|c|c|c|c|c|c|}
\hline \multirow{2}{*}{ Education level } & \multirow[b]{2}{*}{ All } & \multicolumn{4}{|c|}{ Female } & \multicolumn{4}{|c|}{ Male } \\
\hline & & All & $65-69$ & $70-74$ & $75-80$ & All & $65-69$ & $70-74$ & $75-80$ \\
\hline Illiterate & 28.4 & 50.2 & 45.5 & 54.6 & 51.8 & 10.8 & 9.7 & 10.6 & 12.8 \\
\hline Uncompleted primary & 50.8 & 39.3 & 40.3 & 35.9 & 42.8 & 60.0 & 55.6 & 65.1 & 61.0 \\
\hline Completed primary & 13.9 & 7.7 & 9.3 & 7.9 & 4.4 & 18.9 & 19.6 & 16.6 & 20.6 \\
\hline Uncompleted secondary & 3.6 & 1.9 & 3.7 & 0.6 & 0.5 & 5.0 & 7.4 & 3.4 & 3.2 \\
\hline Completed secondary or higher & 3.3 & 1.0 & 1.2 & 1.0 & 0.5 & 5.2 & 7.7 & 4.3 & 2.5 \\
\hline Total & 100.0 & 100.0 & 100.0 & 100.0 & 100.0 & 100.0 & 100.0 & 100.0 & 100.0 \\
\hline Observations & 3947 & 1760 & 730 & 621 & 409 & 2187 & 905 & 679 & 603 \\
\hline
\end{tabular}

We include a dummy variable indicating consumption of tobacco, either in the present or in the past. In this respect, neurological evidence (Cervilla et al., 2000) suggest that smoking seems to be a risk factor for cognitive impairment in old-age individuals, and that moderate alcohol drinking is preventive. A dummy variable indicating retirement ${ }^{4}$ is also added as a control in light of the so-called "mental retirement" effect (Rohwedder and Willis, 2010). This means that an individual who leaves work for retirement might be more likely to face an acceleration in his cognitive decline trend because retirement is, generally, less stimulating than work for cognitive maintenance.

Schooling is an important factor associated with cognition abilities in later-life. For instance, Glymour et al. (2008) report a significant and positive effect of education on memory among the elderly. A recent study by Banks and Mazzonna (2012), based on a regression discontinuity design, supports the hypothesis that an increase in compulsory education affected old-age cognitive abilities in England. In our sample, more than one-fourth of total elderly are illiterate (28.4 percent) and almost 80 percent have not even completed primary school.

Given the characteristics of our sample, it is not surprising that Table 4 reports large gender differences in educational attainment. For instance, half of the female population is illiterate, while this is the case for one-tenth of the male population. Moreover, nearly 90 and 70 percent of females and males, respectively, have not even completed primary education.

Under the same reasoning of disparities in the access of resources, particularly in the past, when the individuals of our sample acquired most of their human capital, we include controls for ethnic groups. Thus, we use a dummy variable for whether the respondent's mother tongue is indigenous (Quechua, Aymara or other indigenous tongue) or in contrast, Spanish.

\section{Results}

\subsection{Main Results}

Columns 1-5 of Table 5 show the OLS estimations of the previously described cognitive scores in standardized form. Columns 6 and 7 report summary measures that we will discuss further.

\footnotetext{
${ }^{4}$ Treat both retirees and unemployed as retired. In our sample, 71 percent are working, 28 percent are retired and only 1 percent is unemployed.
} 
Table 5

OLS estimation of the cognitive z-score.

\begin{tabular}{|c|c|c|c|c|c|c|c|}
\hline \multirow{3}{*}{ Variable } & \multirow{3}{*}{$\begin{array}{c}\text { Episodic memory } \\
(1) \\
\text { Total }\end{array}$} & \multicolumn{4}{|c|}{ Mental intactness } & \multicolumn{2}{|c|}{ Overall } \\
\hline & & $(2)$ & (3) & (4) & $(5)$ & (6) & $(7)$ \\
\hline & & Orientation & Command & Drawing & Total & Additive & PCA \\
\hline \multirow[t]{2}{*}{ Female } & $0.167^{* * *}$ & $-0.203^{* * *}$ & $0.061^{*}$ & $-0.127^{* * *}$ & $-0.157^{* * *}$ & -0.011 & 0.012 \\
\hline & $(0.039)$ & $(0.037)$ & $(0.037)$ & $(0.037)$ & $(0.036)$ & $(0.036)$ & $(0.036)$ \\
\hline \multirow[t]{2}{*}{ Age } & $-0.027^{* * *}$ & $-0.022^{* * *}$ & -0.003 & $-0.018^{* * *}$ & $-0.022^{* * *}$ & $-0.029 * * *$ & $-0.029 * * *$ \\
\hline & $(0.004)$ & $(0.004)$ & $(0.003)$ & $(0.004)$ & $(0.003)$ & $(0.003)$ & $(0.004)$ \\
\hline \multirow{2}{*}{$\begin{array}{l}\text { Mother tongue is } \\
\text { indigenous }\end{array}$} & 0.059 & 0.063 & 0.037 & 0.001 & 0.063 & 0.073 & 0.083 \\
\hline & $(0.082)$ & $(0.071)$ & $(0.085)$ & $(0.070)$ & $(0.072)$ & $(0.073)$ & $(0.076)$ \\
\hline \multirow[t]{2}{*}{ Urban } & $0.151^{* *}$ & 0.014 & 0.052 & 0.085 & 0.052 & $0.117^{*}$ & $0.128^{*}$ \\
\hline & $(0.077)$ & $(0.066)$ & $(0.075)$ & $(0.075)$ & $(0.069)$ & $(0.071)$ & $(0.075)$ \\
\hline \multirow[t]{2}{*}{ Retired } & $-0.108^{* * *}$ & $-0.131^{* * *}$ & $-0.065^{*}$ & $-0.089 * *$ & $-0.146^{* * *}$ & $-0.154^{* * *}$ & $-0.153^{* * *}$ \\
\hline & $(0.040)$ & $(0.037)$ & $(0.037)$ & $(0.043)$ & $(0.036)$ & $(0.036)$ & $(0.037)$ \\
\hline \multirow{4}{*}{$\begin{array}{l}\text { Uncompleted } \\
\text { primary education } \\
\text { Completed } \\
\text { primary education }\end{array}$} & $0.245^{* * *}$ & $0.794^{* * *}$ & $0.116^{* * *}$ & $0.528^{* * *}$ & $0.767^{* * *}$ & $0.636^{* * *}$ & $0.601^{* * *}$ \\
\hline & $(0.043)$ & $(0.041)$ & $(0.039)$ & $(0.046)$ & $(0.039)$ & $(0.039)$ & $(0.040)$ \\
\hline & $0.425^{* * *}$ & $0.943^{* * *}$ & $0.163^{* * *}$ & $0.559 * * *$ & $0.906^{* * *}$ & $0.825^{* * *}$ & $0.779 * * *$ \\
\hline & $(0.058)$ & $(0.051)$ & $(0.055)$ & $(0.055)$ & $(0.050)$ & $(0.051)$ & $(0.052)$ \\
\hline \multirow{2}{*}{$\begin{array}{l}\text { Uncompleted } \\
\text { secondary education }\end{array}$} & $0.440^{* * *}$ & $0.931^{* * *}$ & $0.280^{* * *}$ & $0.637^{* * *}$ & $0.963^{* * *}$ & $0.871^{* * *}$ & $0.846^{* * *}$ \\
\hline & $(0.081)$ & $(0.077)$ & $(0.079)$ & $(0.064)$ & $(0.071)$ & $(0.070)$ & $(0.068)$ \\
\hline \multirow{4}{*}{$\begin{array}{l}\text { Completed second. } \\
\text { education or higher } \\
\text { Arm span (z-score) }\end{array}$} & $0.479^{* * *}$ & $0.988^{* * *}$ & $0.310^{* * *}$ & $0.606^{* * *}$ & $1.011^{* * *}$ & $0.923^{* * *}$ & $0.866^{* * *}$ \\
\hline & $(0.094)$ & $(0.084)$ & $(0.095)$ & $(0.071)$ & $(0.081)$ & $(0.083)$ & $(0.083)$ \\
\hline & $0.032^{*}$ & $0.033^{* *}$ & $0.047^{* * *}$ & $0.053^{* * *}$ & $0.056^{* * *}$ & $0.054^{* * *}$ & $0.067^{* * *}$ \\
\hline & $(0.018)$ & $(0.015)$ & $(0.017)$ & $(0.018)$ & $(0.016)$ & $(0.016)$ & $(0.017)$ \\
\hline \multirow{2}{*}{$\begin{array}{l}\text { Haemoglobin } \\
\text { (z-score) }\end{array}$} & $0.037^{* *}$ & $0.050^{* * *}$ & 0.014 & -0.009 & $0.041^{* *}$ & $0.047^{* * *}$ & $0.036^{* *}$ \\
\hline & $(0.018)$ & $(0.016)$ & $(0.016)$ & $(0.017)$ & $(0.016)$ & $(0.016)$ & $(0.016)$ \\
\hline \multirow[t]{2}{*}{ Mental disorders } & $-0.218^{* * *}$ & $-0.098^{* *}$ & $-0.118^{* * *}$ & $-0.117^{* * *}$ & $-0.150 * * *$ & $-0.217^{* * *}$ & $-0.222^{* * *}$ \\
\hline & $(0.045)$ & $(0.040)$ & $(0.043)$ & $(0.044)$ & $(0.042)$ & $(0.043)$ & $(0.044)$ \\
\hline \multirow[t]{2}{*}{ Smoking } & 0.023 & -0.013 & $-0.093^{* *}$ & $-0.073^{*}$ & $-0.066^{*}$ & -0.030 & -0.029 \\
\hline & $(0.042)$ & $(0.037)$ & $(0.041)$ & $(0.040)$ & $(0.036)$ & $(0.036)$ & $(0.036)$ \\
\hline \multirow[t]{2}{*}{ Constant } & $1.660^{* * *}$ & $1.091^{* * *}$ & 0.155 & $0.962^{* * *}$ & $1.093^{* * *}$ & $1.645^{* * *}$ & $1.607^{* * *}$ \\
\hline & $(0.280)$ & $(0.262)$ & $(0.257)$ & $(0.290)$ & $(0.255)$ & $(0.253)$ & $(0.258)$ \\
\hline $\begin{array}{l}\text { District-level } \\
\text { fixed effects }\end{array}$ & Yes & Yes & Yes & Yes & Yes & Yes & Yes \\
\hline Observations & 3947 & 3947 & 3947 & 3947 & 3947 & 3947 & 3947 \\
\hline R-squared & 0.20 & 0.35 & 0.28 & 0.23 & 0.37 & 0.34 & 0.32 \\
\hline
\end{tabular}

Note: Robust standard errors in parentheses. ${ }^{*} \mathrm{p}<0.1{ }^{* *} \mathrm{p}<0.05{ }^{* * *} \mathrm{p}<0.01$.

Each regression includes district-level fixed effects and robust standard errors. As mentioned before, our primary variable of interest is the dummy for female, which is statistically significant across each cognitive measure, although the direction of the relationship differs. Looking at the overall measures of episodic memory and mental intactness, it is revealed that females have better performance in the former, but they perform worse than males in the latter. In terms of magnitude, females have a score in memory intactness that is 0.17 standard deviations larger than the one of males with similar characteristics. Furthermore, we find different results within the mental intactness dimension. Females perform worse than males in orientation and drawing (0.20 and $0.13 \mathrm{SD}$, respectively), but better in the command component (0.06 SD). Interestingly, the direction of these results in episodic memory and mental intactness are similar to those in Lei et al. $(2012,2014)$ who analyse gender disparities in cognition among Chinese individuals 
aged 45 and over.

Regarding other socio-demographic variables, the relationship between age and each cognitive measure is negative (about $0.02 \mathrm{SD}$ ) and seems stable across the cognitive measures, with the exception of the command component where its coefficient is much smaller and not significant. There is not a significant relationship between the mother tongue and cognition. Furthermore, the inclusion of this variable also helps to control for any bias in the reading and understanding of the survey questions during the interview. Living in an urban area is only significant and positive in the regression for episodic memory.

Retirement is always statistically significant and negatively associated with each measure of cognition. Retirement is associated with a decrease of $0.11 \mathrm{SD}$ and $0.15 \mathrm{SD}$ in the overall measures of episodic memory and mental intactness, respectively. As expected, the role of education on cognitive performance is remarkable. The reference category for the education variables is being illiterate, so that simply moving to the level of uncompleted primary education can raise the performance in episodic memory by $0.25 \mathrm{SD}$ and in mental intactness by $0.77 \mathrm{SD}$. The estimated coefficients of each level of education reveal that the association with education is more important in orientation and less important in command. As we mentioned above, females have significantly less education than males; therefore, we can conjecture that the test of command is capturing some abilities more present in females than in males. Another possibility is that the type of daily activities performed by females is more protective of certain areas of cognition, in contrast to physical work, which is the main activity of working males in our sample (about 87 percent of working elderly males work in agriculture, cattle and construction, while this figure is 68 percent for working females).

In regard to nutritional status we report a positive and statistically significant association of the standardized arm-span (a better measure than height in the old-age population) with each cognitive measure. As discussed before, the arm-span is indicative of the influence of childhood nutrition in cognitive ability development. Recall that arm-span is highly correlated with height and that this has been found to be associated with cognitive development in adulthood (Case and Paxson, 2008). The association between arm-span and cognition ranges from 0.03 SD to 0.06 SD, which is in line with the recent empirical literature concerning the long-term effects of childhood development on current outcomes. Moreover, the relationship between current nutritional status and cognition is measured with the level of haemoglobin. We find a positive and statistically significant association of this variable with the overall measures of episodic memory and mental intactness (in both cases of $0.04 \mathrm{SD}$ ). However, within mental intactness, the role of haemoglobin is only significant and positive for the component of orientation (0.05 SD). As expected, mental health related diseases is negatively associated with each cognitive measure, which is noticeably sizable in the case of episodic memory (-0.22 SD).

There is also evidence of a negative and significant association between smoking and the overall measure of mental intactness (in particular with the command and drawing components). This, however, is not the case with memory. Similarly, Guven and Lee (2015) do not find a significant association between smoking (past or present) with memory, but they show a negative relationship between smoking and verbal fluency when analysing SHARE data for European

\section{(is) PUCP}


individuals aged 50 and over.

Other studies have found similar evidence to the one in our sample. Females from our sample of elderly poor Peruvians perform better than males in some cognitive abilities. For example, Lei et al. (2014) find that Chinese males are better in mental intactness, and females are better in episodic memory. Evidence from developed countries, where gender disparities in education are lower, also shows that females have better scores in episodic memory but worse scores in orientation, which is a component of mental intactness. In this regard, some authors cite a higher cognitive aptitude of females for episodic memory, whereas males are better on tasks that involve spatial recognition (Lewin et al., 2001; Herlitz and Yonker, 2002).

Finally, the last two columns of Table 5 explore different methods to aggregate the different cognitive ability scores. Two options are considered: the first measure is a score equivalent to the total sum of points obtained in each cognitive test, and the second option is a score predicted from Principal Component Analysis (PCA). Both measures are standardized to have mean zero and standard deviation equal to 1 . Given that the estimated coefficients are similar in magnitude and significance between the two columns, our results do not seem to be driven by the way the scores are aggregated.

Overall, cognition is not associated with gender, conditional on the full set of controls. The overall score hides the gender differences in episodic memory and mental intactness. However, we find that individuals in urban areas have better cognition, which lend support to the existence of persistent differences between urban and rural localities, the latter ones being more likely to suffer from inadequate infrastructure, public services, education, health, market access, etc. It is striking that even in our sample of poor individuals, it is found that regional differences matter.

\subsection{Models with Sex Differentials}

We further analyse the results of previous section with the inclusion of interactions between gender and the other covariates (equation (2)). This specification explores whether the variables associated with cognition present gender differentials, which is of particular interest to assessing why elderly males and females perform differently in each cognitive measure. Table 6 reports the OLS results.

The sex differential association between age and cogntion is only statistically significant and negative in the measure of episodic memory, meaning that older females are doing worse than older males in this cognitive measure. Indigenous mother tongue only penalizes females in orientation. There are not statistically significant sex differential relationships of education for episodic memory and command, but we find significant results for orientation, drawing and the overall measure of mental intactness. These associations can be of a large magnitude. For example, focussing on the overall measure of mental intactness, an illiterate male (all the rest remaining constant) has a score $0.22 \mathrm{SD}$ higher than an illiterate female, but this gap is reduced to $0.07 \mathrm{SD}$ when both have completed secondary education. Smoking has significant differential associations only for the measure of drawing, and indicates that smoking affects males more adversely than females. The rest of the variables do not show a differential relationship by sex in any of the cognitive measures. As expected, long-term and short-term nutritional status plays an important 
Table 6

OLS estimation of the cognitive z-score with interaction effects.

\begin{tabular}{|c|c|c|c|c|c|}
\hline \multirow{3}{*}{ Variable } & \multirow{3}{*}{$\begin{array}{c}\text { Episodic memory } \\
(1) \\
\text { Total }\end{array}$} & \multicolumn{4}{|c|}{ Mental intactness } \\
\hline & & (2) & (3) & (4) & $(5)$ \\
\hline & & Orientation & Command & Drawing & Total \\
\hline \multirow[t]{2}{*}{ Female } & $1.099 * *$ & -0.635 & 0.350 & 0.483 & -0.217 \\
\hline & $(0.541)$ & $(0.495)$ & $(0.491)$ & $(0.566)$ & $(0.482)$ \\
\hline \multirow[t]{2}{*}{ Age } & $-0.021 * * *$ & $-0.023^{* * *}$ & -0.001 & $-0.012^{* * *}$ & $-0.021 * * *$ \\
\hline & $(0.005)$ & $(0.004)$ & $(0.005)$ & $(0.005)$ & $(0.004)$ \\
\hline \multirow[t]{2}{*}{ Age*Female } & $-0.014^{*}$ & 0.004 & -0.004 & -0.012 & -0.001 \\
\hline & $(0.008)$ & $(0.007)$ & $(0.007)$ & $(0.008)$ & $(0.007)$ \\
\hline \multirow[t]{2}{*}{ Mother tongue is indigenous } & 0.022 & $0.160^{* *}$ & -0.002 & -0.010 & 0.117 \\
\hline & $(0.088)$ & $(0.074)$ & $(0.089)$ & $(0.073)$ & $(0.075)$ \\
\hline \multirow[t]{2}{*}{ Mother tongue is indigenous*Female } & 0.062 & $-0.197 * * *$ & 0.092 & 0.036 & -0.101 \\
\hline & $(0.073)$ & $(0.064)$ & $(0.070)$ & $(0.073)$ & $(0.063)$ \\
\hline \multirow[t]{2}{*}{ Urban } & $0.151^{*}$ & -0.015 & 0.046 & 0.054 & 0.020 \\
\hline & $(0.082)$ & $(0.072)$ & $(0.079)$ & $(0.078)$ & $(0.073)$ \\
\hline \multirow[t]{2}{*}{ Urban*Female } & -0.001 & 0.052 & 0.017 & 0.032 & 0.054 \\
\hline & $(0.066)$ & $(0.062)$ & $(0.062)$ & $(0.068)$ & $(0.059)$ \\
\hline \multirow[t]{2}{*}{ Retired } & $-0.182^{* * *}$ & $-0.142^{* *}$ & -0.066 & $-0.128 * *$ & $-0.164^{* * *}$ \\
\hline & $(0.062)$ & $(0.056)$ & $(0.058)$ & $(0.059)$ & $(0.056)$ \\
\hline \multirow[t]{2}{*}{ Retired*Female } & 0.123 & 0.009 & 0.013 & 0.074 & 0.030 \\
\hline & $(0.080)$ & $(0.074)$ & $(0.074)$ & $(0.084)$ & $(0.073)$ \\
\hline \multirow[t]{2}{*}{ Uncompleted primary education } & $0.218^{* * *}$ & $0.652^{* * *}$ & $0.183^{* * *}$ & $0.347^{* * *}$ & $0.646^{* * *}$ \\
\hline & $(0.078)$ & $(0.075)$ & $(0.068)$ & $(0.081)$ & $(0.072)$ \\
\hline \multirow[t]{2}{*}{ Completed primary education } & $0.435^{* * *}$ & $0.763^{* * *}$ & $0.221^{* * *}$ & $0.381 * * *$ & $0.752^{* * *}$ \\
\hline & $(0.087)$ & $(0.081)$ & $(0.080)$ & $(0.087)$ & $(0.079)$ \\
\hline \multirow[t]{2}{*}{ Uncompleted secondary education } & $0.452^{* * *}$ & $0.701^{* * *}$ & $0.367^{* * *}$ & $0.480^{* * *}$ & $0.789 * * *$ \\
\hline & $(0.110)$ & $(0.105)$ & $(0.103)$ & $(0.093)$ & $(0.098)$ \\
\hline \multirow[t]{2}{*}{ Completed secondary education or higher } & $0.485^{* * *}$ & $0.851^{* * *}$ & $0.369 * * *$ & $0.474^{* * *}$ & $0.901^{* * *}$ \\
\hline & $(0.113)$ & $(0.104)$ & $(0.113)$ & $(0.095)$ & $(0.101)$ \\
\hline \multirow[t]{2}{*}{ Uncompl. primary educ. ${ }^{*}$ Female } & 0.057 & $0.170^{*}$ & -0.098 & $0.258 * * *$ & $0.148^{*}$ \\
\hline & $(0.093)$ & $(0.091)$ & $(0.083)$ & $(0.100)$ & $(0.087)$ \\
\hline Compl. primary educ. ${ }^{*}$ Female & -0.080 & $0.326 * * *$ & -0.064 & $0.291 * *$ & $0.286 * * *$ \\
\hline & $(0.123)$ & $(0.111)$ & $(0.112)$ & $(0.116)$ & $(0.109)$ \\
\hline Uncompl. secondary educ. ${ }^{*}$ Female & -0.060 & $0.504^{* * *}$ & -0.162 & $0.243^{*}$ & $0.368 * * *$ \\
\hline & $(0.163)$ & $(0.154)$ & $(0.161)$ & $(0.130)$ & $(0.141)$ \\
\hline Compl. secondary educ. or higher*Female & -0.042 & 0.150 & -0.033 & 0.191 & 0.144 \\
\hline & $(0.282)$ & $(0.240)$ & $(0.223)$ & $(0.227)$ & $(0.248)$ \\
\hline Arm span (z-score) & 0.028 & $0.038^{* *}$ & $0.063^{* * *}$ & $0.061^{* * *}$ & $0.068^{* * *}$ \\
\hline & $(0.022)$ & $(0.019)$ & $(0.022)$ & $(0.020)$ & $(0.019)$ \\
\hline Arm span (z-score) ${ }^{*}$ Female & 0.009 & -0.009 & -0.038 & -0.017 & -0.026 \\
\hline & $(0.033)$ & $(0.030)$ & $(0.033)$ & $(0.034)$ & $(0.031)$ \\
\hline Haemoglobin (z-score) & 0.023 & $0.058 * * *$ & 0.018 & -0.010 & $0.048^{* *}$ \\
\hline & $(0.022)$ & $(0.021)$ & $(0.020)$ & $(0.020)$ & $(0.019)$ \\
\hline Haemoglobin (z-score)*Female & 0.030 & -0.020 & -0.008 & 0.010 & -0.015 \\
\hline & $(0.033)$ & $(0.031)$ & $(0.029)$ & $(0.034)$ & $(0.030)$ \\
\hline Mental disorders & $-0.182^{* * *}$ & $-0.117^{* *}$ & $-0.158 * * *$ & $-0.149 * * *$ & $-0.188^{* * *}$ \\
\hline & $(0.059)$ & $(0.051)$ & $(0.055)$ & $(0.053)$ & $(0.052)$ \\
\hline Mental disorders*Female & -0.065 & 0.032 & 0.083 & 0.054 & 0.071 \\
\hline & $(0.085)$ & $(0.075)$ & $(0.077)$ & $(0.083)$ & $(0.077)$ \\
\hline Smoking & 0.031 & -0.007 & $-0.103^{* *}$ & $-0.098^{* *}$ & $-0.071^{*}$ \\
\hline & $(0.044)$ & $(0.038)$ & $(0.044)$ & $(0.042)$ & $(0.038)$ \\
\hline Smoking*Female & -0.060 & -0.067 & 0.076 & $0.253^{* *}$ & 0.041 \\
\hline & $(0.130)$ & $(0.120)$ & $(0.117)$ & $(0.114)$ & $(0.111)$ \\
\hline Constant & $1.252^{* * *}$ & $1.310^{* * *}$ & -0.003 & $0.761^{* *}$ & $1.144^{* * *}$ \\
\hline & $(0.356)$ & $(0.327)$ & $(0.334)$ & $(0.332)$ & $(0.319)$ \\
\hline District-level fixed effects & Yes & Yes & Yes & Yes & Yes \\
\hline Observations & 3947 & 3947 & 3947 & 3947 & 3947 \\
\hline R-squared & 0.21 & 0.36 & 0.28 & 0.23 & 0.37 \\
\hline
\end{tabular}

Note: Robust standard errors in parentheses. ${ }^{*} \mathrm{p}<0.1{ }^{* *} \mathrm{p}<0.05 * * * \mathrm{p}<0.01$. 
role in predicting cognitive functioning in old age, but they do not appear to be different between men and women. It seems that policies directed to improve the nutritional status of children and the elderly are important to enhance the cognitive reserve in old-age, and that policies giving more educational opportunities to girls can help to close the gap in cognitive functioning.

\section{Discussion}

In this paper we have reported important gender differences in a range of different cognitive abilities in a sample of elderly individuals living in poverty in Peru. After controlling for a comprehensive set of variables related to cognition, we show that females are better off than males regarding episodic memory, but worse off in mental intactness. This last cognitive measure is an overall indicator that includes three components: command (able to follow a series of orders), orientation and drawing (assessing visual-spatial abilities). Females are better off than males regarding command, but worse off regarding orientation and drawing. In contrast to what one would expect for the elderly poor, females are not always worse than males in terms of cognitive functioning. The assessment of an overall measure of cognition that includes all the cognitive tests reveals that gender does not matter in cognition but regional differences do. This lends support to persistent differences between urban and rural localities.

The sizeable association between education and cognitive functioning, together with the reported results of positive associations between the quality of childhood nutrition and cognitive abilities, confirm the long-term impacts of early life developments on current outcomes. Therefore, policies directed to improving early childhood development are expected to have a positive influence in later-life. Two other covariates with a major influence in old-age cognition are current nutritional state (measured with haemoglobin levels) and the existence of diseases related to mental health. In this case, public policies directed to the current elderly poor group might have an important impact on their well-being. For instance, raising the quality of nutritional intake and medically attending to chronic mental diseases may be relevant for delaying cognitive decline in old-age.

With cross-section data and no means to capture exogenous variation in education and other covariates of interest (e.g. nutritional status), any causal interpretation is clearly hazardous. It will be interesting to re-examine the effects of education on cognitive functioning whether an exogenous educational policy existed at the time the individuals made their educational choices and this affected different cohorts. However, no such policy existed for the age group analysed (65-80). Another way of attempting a causal examination could be analysing the effects of the Pension 65 program on nutritional status and then on cognitive functioning, but that analysis is beyond the scope of this study. 


\section{References}

Banks, J., and Mazzonna, F. (2012). The Effect of Education on Old Age Cognitive Abilities: Evidence from a Regression Discontinuity Design. The Economic Journal 122, 418-448.

Case, A., and Paxson, C. (2008). Height, Health and Cognitive Function at Older Ages. American Economic Review 98, 463-467.

Cervilla, J., Prince M., and Mann, A. (2000). Smoking, drinking, and incident cognitive impairment: a cohort community based study included in the Gospel Oak project. Journal of Neurology, Neurosurgery and Psychiatry 68, 622-626.

Chodosh, J., Kado, D., Seeman, T., and Karlamangla, A. (2007). Depressive symptoms as a predictor of cognitive decline: MacArthur Studies of Successful Aging. American Journal of Geriatric Psychiatry 15, 406-415.

De Lucia, E., Lemma, F., Tesfaye, F., Demisse, T., and Ismail, S. (2002). The use of armspan measurement to assess the nutritional status of adults in four Ethiopian ethnic groups. European Journal of Clinical Nutrition 56(2), 91-95.

Dotson, V., Resnick, S., and Zonderman, A. (2008). Differential association of concurrent, baseline, and average depressive symptoms with cognitive decline in older adults. American Journal of Geriatric Psychiatry 16, 318-330.

Folstein, M., Folstein, S., and McHugh, P. (1975). Mini-mental state: A practical method for grading the cognitive state of patients for the clinician. Journal of Psychiatric Research 12(3), 189-98.

Glymour, M., Kawachi, I., Jencks, C., and Berkman, L. (2008). Does childhood schooling affect old age memory or mental status? Using state schooling laws as natural experiments. Journal of Epidemiology and Community Health 62(6), 532-537.

Guven, C., and Lee, W. (2013). Height and Cognitive Function at Older Ages: Is Height a Useful Summary Measure of Early Childhood Experiences? Health Economics 22, 224-233.

Guven, C., and Lee, W. (2015). Height, Ageing and Cognitive Abilities across Europe. Economics E Human Biology 16, 16-29.

Hong, C. et al. (2013). Anemia and risk of dementia in older adults: findings from the Health ABC study. Neurology 81(6), 528-533.

Herlitz, A., and Yonker, J. (2002). Sex Differences in Episodic Memory: The Influence of Intelligence. Journal of Clinical and Experimental Neuropsychology 24(1), 107-114.

Kwok, T., and Whitelaw, M. (1991). The use of armspan in nutritional assessment of the elderly. Journal of the American Geriatrics Society 39(5), 492-6.

Kwok, T., Lau, E., and Woo, J. (2002). The prediction of height by armspan in older Chinese people. Annals of Human Biology 29(6), 649-56.

Lee, J., Shih, R., Feeney, K., and Langa, K. (2014). Gender disparity in late-life cognitive functioning in india: findings from the longitudinal aging study in india. Journals of Gerontology, Series B: Psychological Sciences and Social Sciences 69(4), 603-61.

Lei, X., Hu. Y., McArdle, J., Smith, J., and Zhao, Y. (2012). Gender Differences in Cognition among Older Adults in China. Journal of Human Resources 47(4), 951-971.

\section{(is) PUCP}


Lei, X., Smith, J.P., Sun, X., and Zhao, Y. (2014). Gender Differences in Cognition in China and Reasons for Change over Time: Evidence from CHARLS. Journal of Economics of Ageing 4, 46-51.

Lewin, C., Wolgers, G., and Herlitz, A. (2001). Sex Differences Favoring Women in Verbal but not in Visuospatial Episodic Memory. Neuropsychology 15(2), 165-183.

Maurer, J. (2010). Height, Education and Cognitive Function at Older Ages: International Evidence from Latin America and the Caribbean. Economics and Human Biology 8, 168-176.

Maurer, J. (2011). Education and male-female differences in later-life cognition: international evidence from Latin America and the Caribbean. Demography 48(3), 915-930.

McFadden, D. (2008). Human capital accumulation and depreciation. Review of Agricultural Economics 30, 379-385.

Rohwedder, S., and Willis, R. (2010). Mental retirement. Journal of Economic Perspectives 24(1), $1-20$.

Yount, K., Hoddinott, J., Stein, A., and DiGirolamo, A. (2009). Individual Capital and cognitive Ageing in Guatemala. Population Studies 63, 295-306. 